\title{
Health status, use of healthcare, and socio-economic implications of cancer survivorship in Portugal: results from the Fourth National Health Survey
}

\author{
Luís Pacheco-Figueiredo • Nuno Lunet
}

Received: 4 February 2014 / Accepted: 19 May 2014

(C) Springer Science+Business Media New York 2014

\begin{abstract}
Purpose Understanding the morbidity and socio-economic implications of cancer survivorship is essential for a comprehensive management of oncological diseases. We compared cancer survivors (CS) with the general population regarding health status, use of healthcare resources and socio-economic condition.

Methods We analyzed data from a representative sample of the Portuguese population aged $\geq 15$ years $(n=35,229)$. We defined three groups of CS, according to the time since diagnosis and the latest cancer treatment: CS 1 diagnosis within 12 months of interview; CS 2 diagnosis more than 12 months before and treatment in the previous 12 months; CS 3 diagnosis and treatment more than 12 months before. These were compared with the general population, adjusting for differences in sex, age, and place of residence.

Results The prevalence of CS was $2.2 \%$ (CS 1: $0.2 \%$; CS 2: $0.9 \%$, CS 3: $1.1 \%$ ). Self-perceived health status was worse among CS and short-time incapacity more frequent among CS 1 and CS 2 . Health expenses were higher in the early stages of survivorship. Lower household income and financial difficulties were more frequent in CS 1 and CS 3 men, respectively. Conclusion This study confirmed the higher consumption of healthcare resources and worse financial situation among CS.
\end{abstract}

L. Pacheco-Figueiredo $\cdot N$. Lunet $(\bowtie)$

Department of Clinical Epidemiology, Predictive Medicine and Public Health, Faculty of Medicine, University of Porto, Al. Prof. Hernâni Monteiro, 4200-319 Porto, Portugal e-mail: nlunet@med.up.pt

L. Pacheco-Figueiredo $\cdot N$. Lunet

Institute of Public Health, University of Porto (ISPUP), Porto,

Portugal

L. Pacheco-Figueiredo

Life and Health Sciences Research Institute (ICVS), School of Health

Sciences, University of Minho, Braga, Portugal
Implications for Cancer Survivors Our study provides valuable information for understanding the global impact of cancer survivorship.

Keywords Neoplasms $\cdot$ Survival $\cdot$ Health survey $\cdot$ Portugal

\section{Introduction}

An increasing number of cancer patients has been observed in the last decades, especially due to population growth, aging and screening [1-5]; in 2012, over six million new cases were estimated to have occurred in the more developed regions [6]. Concurrently, early diagnosis and effective treatment resulted in improved survival [7]; the 5-year relative survival for all cancers was $52.0 \%$ among cases diagnosed in Europe between 1995 and 1999 [8], and 68.1\% in the USA in 20032009 [9]. In Portugal, almost 50,000 new cancers are diagnosed each year [6]; among patients diagnosed in the North during 2005-2006, the 5-year relative survival was above $60 \%[10]$.

The morbidity and socio-economic effects of cancer diagnosis and treatment are important components of its overall burden among the growing population of living persons ever diagnosed with cancer [11, 12]. Cancer survivors often suffer from persistent symptoms (pain, distress, fatigue or cognitive impairment), as well as employment changes and financial difficulties, that could affect not only the patient but also their whole families, among other short and long term effects [13, 11]. Assessing the impact of these phenomena in different settings is needed to support a more comprehensive management of oncological diseases.

Therefore, we aimed to assess the impact of cancer survivorship on health status, use of healthcare and socio-economic 
condition, using data from the latest Portuguese National Health Survey.

\section{Methods}

The present analysis is based on data collected as part of the fourth National Health Survey (IV-NHS), which is a nationwide community-based cross-sectional study [14].

Population sampling and data collection

A sample of households was defined, using data from the 2001 Population and Housing Census, to be used as the sampling frame for household surveys conducted by the National Institute of Statistics (INE). It included 1,408 geographical units with at least 240 households each, selected systematically within larger geographical strata, with a probability proportional to the number of households in each unit. A random sample of the households was then selected and all dwellers were eligible.

During a total of 52 weeks, between February 2005 and January 2006, 41,193 persons from 15,239 households were evaluated. All the information was collected directly from the individuals or from proxies, through computer-assisted interviews performed by trained interviewers.

The participants that reported a previous cancer diagnosis (medically confirmed) were considered cancer survivors (CS) and were further divided in three groups: (a) those with the diagnosis in the previous 12 months (CS 1); (b) those with a diagnosis more than 12 months before the interview, but having been submitted to a cancer treatment in the previous 12 months (CS 2); (c) those with cancer diagnosis and treatment more than 12 months before (CS 3).

A detailed description of the assessment of the participants' health status, healthcare consumption, and socio-economic characteristics is presented in footnotes in the tables and figures depicting the results.

\section{Statistical analysis}

Data analysis was restricted to participants aged $\geq 15$ years, corresponding to a sample of 35,229 respondents. The evaluation of the use of preventive care procedures and the financial status of the respondents was accomplished only in subsamples of approximately one quarter of the total sample, evaluated in weeks of data collection 27 to 39 and 40 to 52 , respectively. Data on the general health status and quality of life domains of the questionnaire were collected only from non-proxy respondents (approximately two thirds of the sample). All analyses were conducted with STATA $^{\circledR}$, version 11.1 (StataCorp LP, College Station, TX, USA), using sampling weights, calculated based on the inverse of the probability of selection of each sampling unit, further corrected for nonresponses and for the effective number of subjects evaluated, regarding the age and sex structures.

We computed weighted prevalences and corresponding $95 \%$ confidence intervals $(95 \% \mathrm{CI})$, as well as age-, region-, and education-adjusted prevalence ratios (PR), using Poisson regression [15] to compare each group of CS, namely CS 1, $\mathrm{CS} 2$, and CS 3, with the participants not reporting a previous diagnosis of cancer (NC). To analyze data on family income we assigned to each category the corresponding midpoint and treated the variable as continuous; data were described with box-and-whisker plots and different groups were compared using multivariable linear regression.

\section{Results}

A total of 784 participants were cancer survivors, corresponding to a weighted prevalence of $2.2 \%$ (95\%CI: 1.9-2.4), from which $71(0.2 \%, 95 \% \mathrm{CI}: 0.1-0.2)$ reported a cancer diagnosis in the last 12 months (CS 1), $321(0.9 \%, 95 \%$ CI: $0.7-1.1)$ were diagnosed a cancer more than 12 months before, but had been treated during the preceding 12 months (CS 2), and 392 $(1.1 \%, 95 \%$ CI: $0.9-1.3)$ had been diagnosed and treated for cancer more than 12 months before (CS 3).

The percentage of men was lowest in CS 3 (28.9\%) and ranged between $48.0 \%$ and $57.4 \%$ in NC and CS 1, respectively. CS were more frequently aged above 65 years (percentage ranging from $52.7 \%$ of CS 1 to $43.7 \%$ of CS 3 ) than $\mathrm{NC}(19.7 \%)$. Less educated participants were more prevalent among CS (Table 1).

Participants' health status and healthcare consumption

Compared to NC, CS reported an approximately $30 \%$ higher prevalence of bad perceived health status, regardless of the time since the diagnosis, while significantly higher levels of short-term incapacity were observed only in CS $1(\mathrm{PR}=3.7)$ and CS 2 ( $P R=2.0)$ (Fig. 1). CS had a $20 \%$ higher prevalence of medication consumption, though the PR for medical consultations decreased from 1.5 in CS 1 to 1.2 in CS 3 (Fig. 1). Regarding preventive care, CS reported an approximately $20 \%$ higher prevalence of cholesterol evaluation, and smaller differences were observed for blood pressure assessment, which was significantly more frequent only in CS 1 and CS $2(\mathrm{PR}=1.1)$. All groups reported a low frequency of flu vaccination, though a non-significantly $20 \%$ higher prevalence was observed among CS 2 and CS 3 (Fig. 1). The results were similar when data were analyzed separately for men and women (data not shown). 
Table 1 Socio-demographic characteristics of cancer survivors and non-cancer individuals

\begin{tabular}{|c|c|c|c|c|}
\hline & \multirow{2}{*}{$\begin{array}{l}\mathrm{NC} \\
\%(95 \% \mathrm{CI})^{\mathrm{a}}\end{array}$} & \multicolumn{3}{|l|}{ Cancer survivor } \\
\hline & & $\begin{array}{l}\text { CS } 1 \\
\%(95 \% C I)^{a}\end{array}$ & $\begin{array}{l}\text { CS } 2 \\
\%(95 \% C I)^{a}\end{array}$ & $\begin{array}{l}\text { CS } 3 \\
\%(95 \% \mathrm{CI})^{\mathrm{a}}\end{array}$ \\
\hline \multicolumn{5}{|l|}{ Gender } \\
\hline Female & $52.0(51.0-53.0)$ & $42.6(20.2-65.0)$ & $47.1(36.7-57.5)$ & $71.1(63.5-78.8)$ \\
\hline Male & $48.0(47.0-49.0)$ & $57.4(35.0-79.8)$ & $52.9(42.5-63.2)$ & $28.9(21.2-36.5)$ \\
\hline \multicolumn{5}{|c|}{ Age (years) } \\
\hline $15-34$ & $33.8(32.7-34.8)$ & $4.3(0.0-11.0)$ & $2.1(0.0-4.6)$ & $12.6(5.4-19.8)$ \\
\hline $35-64$ & $46.6(45.6-47.6)$ & $42.9(19.4-66.5)$ & $50.2(39.8-60.7)$ & $43.7(35.2-52.2)$ \\
\hline$\geq 65$ & $19.7(18.9-20.4)$ & $52.7(29.2-76.2)$ & $47.6(37.2-58.0)$ & $43.7(35.4-52.0)$ \\
\hline \multicolumn{5}{|c|}{ Education (years) } \\
\hline None & $11.8(11.1-12.4)$ & $21.3(4.7-37.9)$ & $21.3(13.1-29.4)$ & $18.4(12.1-24.7)$ \\
\hline $1-4$ & $31.6(30.7-32.5)$ & $51.3(28.0-74.6)$ & $56.2(46.0-66.5)$ & $43.6(35.1-52.1)$ \\
\hline $5-6$ & $14.9(14.1-15.7)$ & $14.9(0.0-33.6)$ & $5.5(1.2-9.8)$ & $13.1(6.9-19.3)$ \\
\hline $7-9$ & $14.7(14.0-15.5)$ & $5.3(0.0-10.7)$ & $7.1(1.9-12.3)$ & $10.3(4.6-16.0)$ \\
\hline $10-12$ & $14.7(14.0-15.4)$ & $5.4(0.0-10.8)$ & $6.1(0.7-11.5)$ & $7.3(3.7-10.8)$ \\
\hline$>12$ & $12.3(11.6-13.0)$ & $1.9(0.0-4.5)$ & $3.8(0.0-7.9)$ & $7.3(3.0-11.6)$ \\
\hline
\end{tabular}

NC Participants not reporting a previous diagnosis of cancer, CS 1 Cancer survivors with a cancer diagnosis in the previous 12 months, CS 2 Cancer survivors with a cancer diagnosis with more than 12 months, but have been submitted to treatment in the 12 months before, CS 3 Cancer survivors with a cancer diagnosis or treatment with more than 12 months

${ }^{\mathrm{a}}$ Weighted prevalence

Among women, mammography use was more frequent in cancer survivors, being especially higher in the CS 1 group
$(\mathrm{PR}=4.3)$. The use of cervical cytology was more frequent only in $\mathrm{CS} 1(\mathrm{PR}=5.3)$ (Fig. 1).

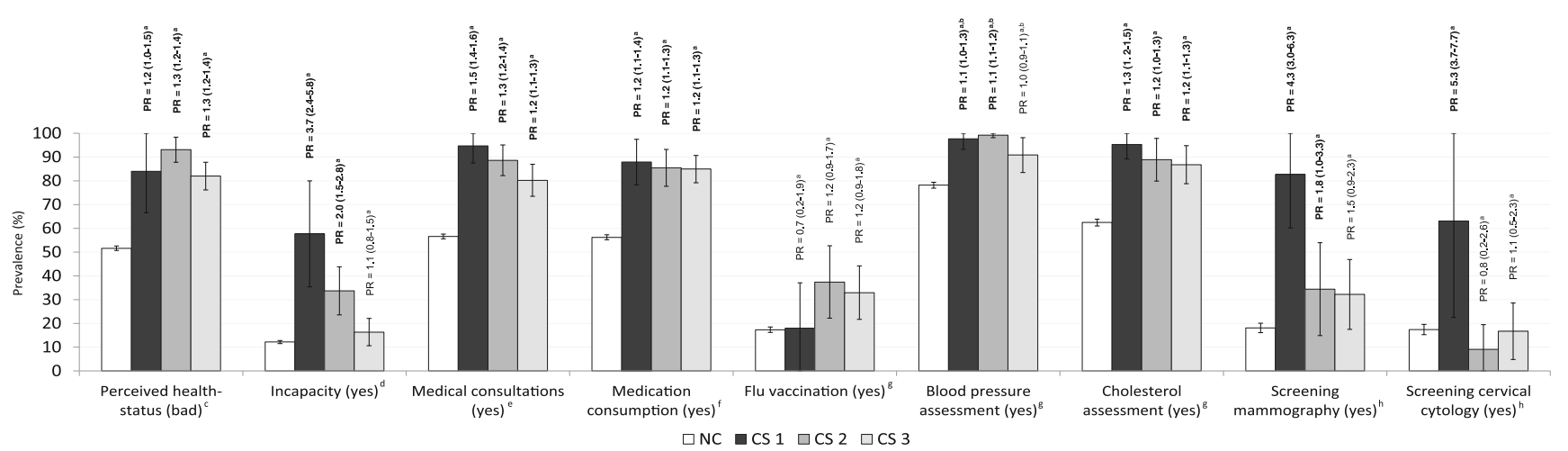

Fig. 1 Participant's health status and healthcare consumption, in noncancer participants and cancer survivors. (a) Age-, region-, and education-adjusted prevalence ratio and corresponding $95 \%$ confidence interval: PR $(95 \% \mathrm{CI})$. (b) Poisson regression model also included a variable on the history of hypertension. (c) Perceived health status was evaluated with a question asking how the participants classify their health status. They could answer: "very good", "good", "reasonable", "bad" and "very bad". For further analysis the answers were aggregated within "good" (the first three options) and "bad" categories (the last two options). (d) Incapacity was evaluated with the question: "During the last 2 weeks, how many days did you have your ability to accomplish regular activities compromised due to disease, accident, violence or other health problem?"; those respondents that reported at least 1 day were considered to have incapacity. (e) Participants were asked about the number of medical consultations in the previous 3 months. (f) Participants were asked about the consumption of any medicines in the past 2 weeks. $(g)$ Participants were asked about the use of preventive care measures during the previous year: flu vaccination, blood pressure measurement and cholesterol evaluation. (h) Mammography and cervical cytology were evaluated by asking the participants if they had been submitted to the procedure in the previous 12 months, and it was restricted to women evaluated during the weeks 27 to 39. NC Participants not reporting a previous diagnosis of cancer. CS 1 Cancer survivors with a cancer diagnosis in the previous 12 months. CS 2 Cancer survivors with a cancer diagnosis with more than 12 months, but have been submitted to treatment in the 12 months before. CS 3 Cancer survivors with a cancer diagnosis or treatment with more than 12 months 
Socio-economic implications

A higher proportion of CS reported health expenditures in the last 2 weeks, especially in the CS 1 group $(\mathrm{PR}=1.4)$, though differences were not statistically significant. The level of health expenditures was nearly twice higher among CS 1 than in NC; smaller and non-statistically significant differences were observed between CS 2 or CS 3 and NC (Fig. 2). Results were similar when gender stratified analyses were conducted (data not shown).

The household income was lower among male cancer survivors, mainly in the CS 1 group $(\beta=-304.3 ;-431.3$, -117.3 ), but no significant differences were observed among women (Fig. 3).

We found a higher prevalence of financial difficulties among cancer survivors, only among men, which was statistically significant in the $\mathrm{CS} 3$ group $(\mathrm{PR}=2.2)$ (Fig. 4).

\section{Discussion}

The prevalence of CS in the Portuguese adult population was $2.2 \%$ in 2005/2006. CS reported worse health status and a higher consumption of healthcare resources, both for men and women, whereas financial consequences were more frequent in male CS.

The recent estimates of cancer prevalence in the USA (2007) [16] and in the UK (2008) [17], based on data from cancer registries, were $3.9 \%$ and $3.3 \%$, respectively. The lower prevalence observed in our study may reflect the lower crude incidence rates in the Portuguese setting (405.4/100,000 vs. $461.1 / 100,000$ in the USA and $496.9 / 100,000$ in the UK) [18], as well as worse survival among Portuguese cancer patients in comparison with those in the USA and similar to those observed in the UK [7]. On other hand, the present study assessed the prevalence of CS using cross-sectional selfreported data, which may contribute to an overestimation of cancer survivorship due to misclassification of diagnoses of benign conditions as cancer [19].

According to our results the estimated number of CS in Portugal would be approximately 220,000 , whom may be expected to suffer several physical and psychological adverse effects of diagnosis and treatment $[12,11]$. Our results highlight a worse perceived health status among cancer survivors, independently of the survivorship period, in accordance with previous observations in other settings, probably reflecting high levels of bothering symptoms, such as persistent pain, fatigue, distress and cognitive impairment [13, 20,21].

The first 12 months after the diagnosis are often associated with a high symptom burden, especially as a consequence of treatment, which frequently impairs the ability to maintain the regular activities [13]. In accordance, we found the highest

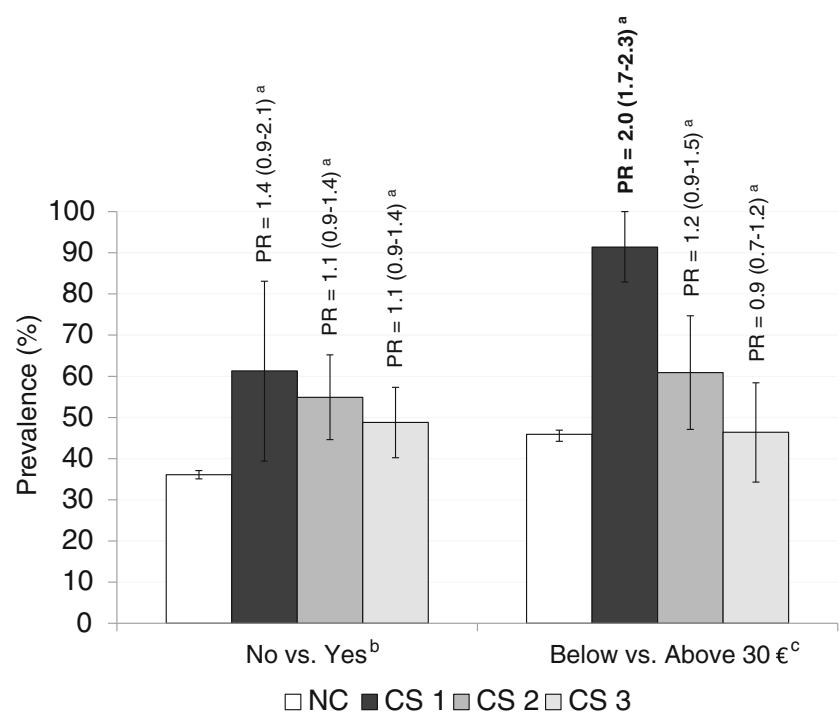

Fig. 2 Health-related expenditures by household members in the previous 2 weeks, in non-cancer participants and cancer survivors. (a) Age-, region-, and education-adjusted prevalence ratio and corresponding $95 \%$ confidence interval: PR $(95 \% \mathrm{CI})$. (b) Participants were asked about the health-related expenditures by household members in the previous 2 weeks (including medical consultations, medications, diagnostic procedures and other treatments). (c) Median ( $30 €$ ) of the level of expenses, among those that reported health-related expenditures. NC Participants not reporting a previous diagnosis of cancer. $C S 1$ Cancer survivors with a cancer diagnosis in the previous 12 months. CS 2 Cancer survivors with a cancer diagnosis with more than 12 months, but have been submitted to treatment in the 12 months before. CS 3 Cancer survivors with a cancer diagnosis or treatment with more than 12 months

prevalence of short-term incapacity among the CS diagnosed more recently.

Despite some heterogeneity across different studies from several countries, cancer survivors often have a greater utilization of healthcare services, which mainly correspond to consultations with the primary care physician and/or the oncologist [22]. The frequency of those contacts with the healthcare system is higher in the first year, mostly related to diagnosis and treatment, and tends to decrease to nearly half during the three subsequent years [22, 23]. Similarly, in our study CS reported a higher frequency of medical consultations during the first 12 months. However, they maintained a pattern of high consumption of medicines for a longer period, possibly reflecting the bothering symptoms and chronic conditions that persist after cancer diagnosis and primary treatment.

Preventive care assumes an important role among cancer survivors, due to their poorer health condition, which is commonly associated with a higher prevalence of comorbidities and an increased risk of second primary tumors [12, 24, 25]. Several studies comparing the use of preventive care between CS and the general population yielded inconsistent results [26, 23, 27-30], which may reflect the fact that these studies were performed in different settings, with heterogeneous models of health financing and accessibility to healthcare services. 
Moreover, there were also differences regarding age and tumor topography distributions, as well as several lengths of time since the diagnosis, which are important determinants of preventive care use [30]. In our study, CS reported a higher frequency of blood pressure and cholesterol evaluations, as well as cancer screening (cervical cytology and mammography) among subjects with a more recent cancer diagnosis; however, the latter may reflect, at least partially, the misclassification of diagnosis mammography exams as screening.

Regarding flu vaccination, we should emphasize the lower proportion of CS undergoing immunization as a public health concern, namely in comparison with observations from other settings [11]. This is especially relevant in our sample since we had more than $20 \%$ of the individuals with age above 65 years and a large percentage of the CS were probably under immunosuppressant treatments, which are some of the established criteria to perform the immunization [31].

Several studies have illustrated the financial impact that comes with the variety of problems posed by a cancer diagnosis [32]. Although in Portugal the payment of cancer treatments is mostly supported by the National Health System, there are studies performed in other settings, mainly in the USA, showing that even for insured patients the cost of cancer diagnosis and treatment can represent a barrier to high-quality care [33]. Out-of-pocket expenses associated with cancer treatment may still be substantial and lead to delay in treatment, noncompliance, exhaustion of savings and personal bankruptcy [34]. In our sample, we found a higher level of health expenditures among cancer survivors, mostly in the first stages of survivorship.

CS also reported lower levels of family income after the cancer diagnosis, which were particularly relevant among male survivors. This decrease is in accordance with the known changes in the working situation among cancer patients, such as unemployment due to incapacity, switch to part-time activities and early-retirement [35]. The high level of health expenditures among CS, concurrently with these lower levels of family income in men, may explain the higher frequency of financial difficulties that we found in male CS, mostly among those surviving for longer periods.

The follow-up of the growing population of CS, which reveals a higher consumption of healthcare resources, may need to be reassigned to primary care services with wellestablished standard protocols of clinical surveillance, in order to decentralize services and facilitate the access of these individuals to healthcare. Policy makers might also have to consider setting up effective supportive programs to help the most socially disadvantaged CS, with the perspective of minimizing the financial difficulties and their negative impact in the quality of life and in the disease survival [36], namely through multidisciplinary interventions to enhance return-towork for CS [37].

Despite the strengths of using a large nationally representative sample with data from the latest Portuguese National
Fig. 3 Household income in the previous month in non-cancer participants and cancer survivors, for women and men. (a) Age-, region-, and education-adjusted coefficients of a linear regression model and corresponding $95 \%$ confidence intervals: $\beta(95 \% \mathrm{CI})$. (b) Overall income of the household in the previous month, by selecting one of ten given categories of income. $N C$ Participants not reporting a previous diagnosis of cancer. CS 1 Cancer survivors with a cancer diagnosis in the previous

12 months. CS 2 Cancer survivors with a cancer diagnosis with more than 12 months, but have been submitted to treatment in the 12 months before. CS 3 Cancer survivors with a cancer diagnosis or treatment with more than 12 months

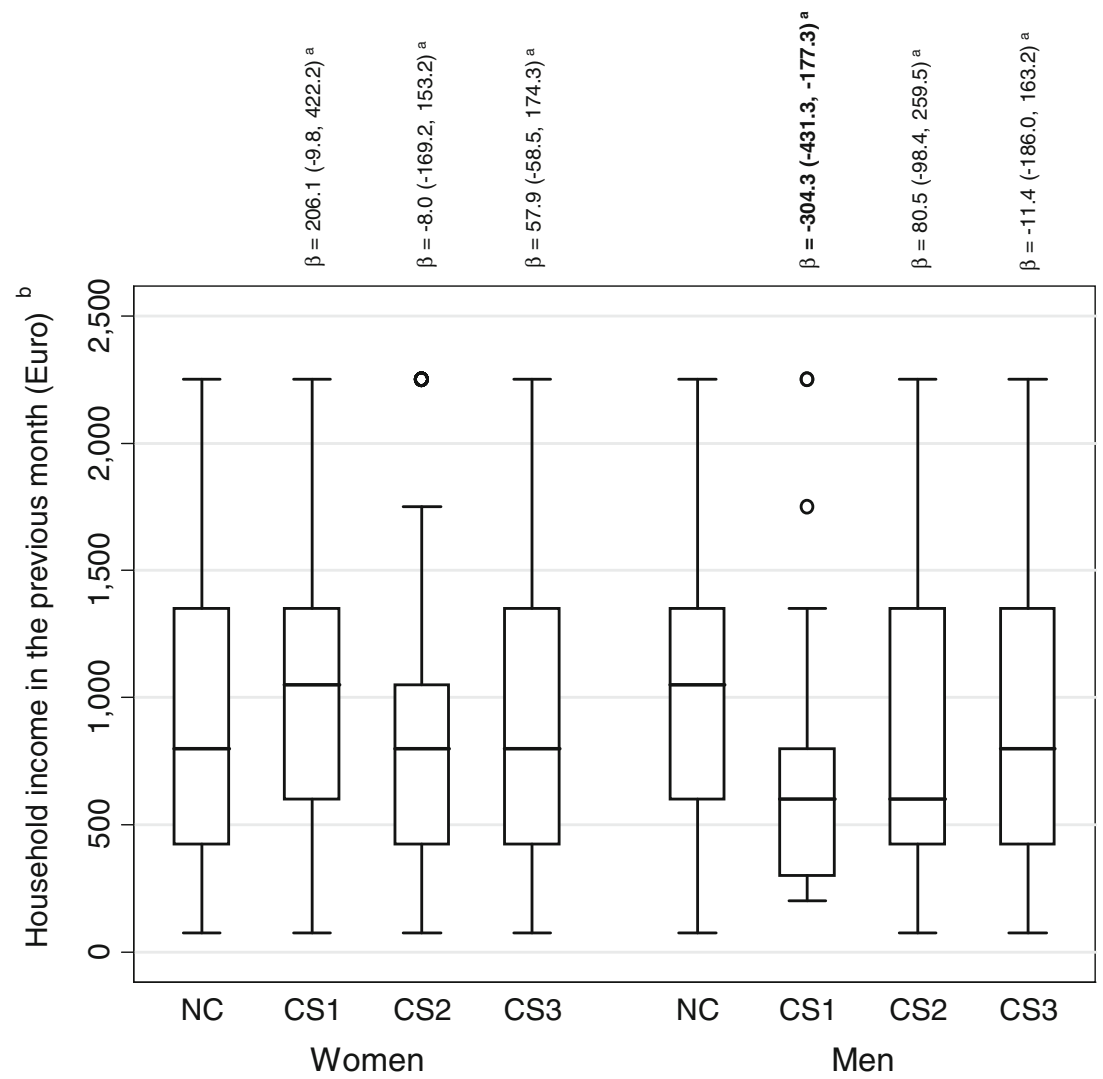




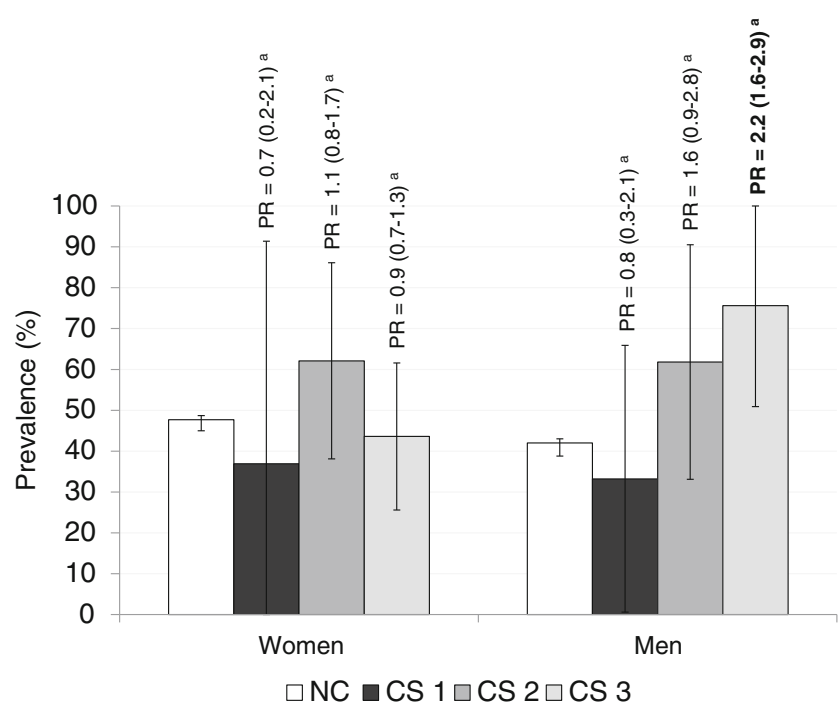

Fig. 4 Reported financial difficulties ${ }^{\mathrm{b}}$ in non-cancer participants and cancer survivors, for women and men. (a) Age-, region-, and educationadjusted prevalence ratio and corresponding $95 \%$ confidence interval: PR ( $95 \%$ CI). (b) Participants were asked if they have enough money to fulfill their basic needs. They could answer: "not at all", "little", "some", "usually have" and "always have". For further analysis the answers were aggregated within "have financial difficulties" (the first three options) and "do not have financial difficulties" categories (the last two options). $N C$ Participants not reporting a previous diagnosis of cancer. CS 1 Cancer survivors with a cancer diagnosis in the previous 12 months. CS 2 Cancer survivors with a cancer diagnosis with more than 12 months, but have been submitted to treatment in the 12 months before. CS 3 Cancer survivors with a cancer diagnosis or treatment with more than 12 months

Health Survey, constituting an important piece of information for understanding the dimension of this problem in Portugal, the present study has some limitations. CS were identified by self-report, and data about stage at diagnosis, treatment, recurrence, or other clinical characteristics were not available. The accuracy of information on a previous cancer diagnosis was improved by considering only those reported to be medically confirmed, but the lack of additional information on these events precluded a finer assessment of the burden of cancer survivorship in Portugal. Data on some variables was available only for subsamples of the participants in the national Health Survey, which compromised the statistical power of the study, but this is not expected to compromise the validity of the conclusions. Also, for some variables proxy respondents were allowed, which may contribute to information bias; however, we conducted sensitivity analyses excluding data obtained from proxies and the conclusions remained essentially the same (data not shown). Although we excluded from our analyses the participants aged $<15$ years, because only 6 CS were observed in this age group, the small proportion of subjects aged 15-34 years among CS 1 and CS 2 could have contributed for spurious age-adjusted estimates; however, a sensitivity analysis including only the participants aged $\geq 35$ years yielded essentially the same results (data not shown). The establishment of causal relationships between the onset of comorbid conditions and the cancer diagnosis or treatment is limited by the cross-sectional design of the study, which also leads to an underrepresentation of newly diagnosed cancers and those with a short survival. Nevertheless, to our knowledge, this is the first study addressing this topic in a representative sample of the Portuguese population and provides valuable information for understanding a different dimension of the burden of cancer survivorship, in addition to increasing the awareness to this growing public health concern, which brings new challenges to healthcare provision and social security.

Acknowledgments The authors thank the National Health Systems Observatory (Observatório Nacional de Saúde), National Institute of Health Dr. Ricardo Jorge (INSA), Ministry of Health and the National Institute of Statistics (INE) for providing the data (Ministério da Saúde, Instituto Nacional de Saúde Dr. Ricardo Jorge; IP, Departamento de Epidemiologia/Instituto Nacional de Estatística: Inquérito Nacional de Saúde 2005/2006). Luís Pacheco-Figueiredo received a grant from the Fundação para a Ciência e a Tecnologia (SFRH/SINTD/60124/2009).

Conflict of interest Luís Pacheco-Figueiredo and Nuno Lunet declare that they have no conflicts of interest.

\section{References}

1. Ferlay J, Steliarova-Foucher E, Lortet-Tieulent J, Rosso S, Coebergh $\mathrm{JW}$, Comber $\mathrm{H}$, et al. Cancer incidence and mortality patterns in Europe: estimates for 40 countries in 2012. Eur J Cancer. 2013;49(6):1374-403. doi:10.1016/j.ejca.2012.12.027.

2. Edwards BK, Howe HL, Ries LA, Thun MJ, Rosenberg HM, Yancik $\mathrm{R}$, et al. Annual report to the nation on the status of cancer, 19731999 , featuring implications of age and aging on U.S. cancer burden. Cancer. 2002;94(10):2766-92.

3. Araujo F, Gouvinhas C, Fontes F, La Vecchia C, Azevedo A, Lunet $\mathrm{N}$. Trends in cardiovascular diseases and cancer mortality in 45 countries from five continents (1980-2010). Eur J Prev Cardiol. 2013. doi: $10.1177 / 2047487313497864$.

4. Amaro J, Severo M, Vilela S, Fonseca S, Fontes F, La Vecchia C, et al. Patterns of breast cancer mortality trends in Europe. Breast. 2013;22(3):244-53. doi:10.1016/j.breast.2013.02.007.

5. Fontes F, Severo M, Castro C, Lourenco S, Gomes S, Botelho F, et al. Model-based patterns in prostate cancer mortality worldwide. Br J Cancer. 2013;108(11):2354-66. doi:10.1038/bjc.2013.217.

6. GLOBOCAN 2012 v1.0, Cancer Incidence and Mortality Worldwide [database on the Internet]. Lyon, France: International Agency for Research on Cancer. 2013. Available from: http://globocan.iarc.fr. Accessed 11 Nov 2013.

7. Coleman MP, Quaresma M, Berrino F, Lutz JM, De Angelis R, Capocaccia R, et al. Cancer survival in five continents: a worldwide population-based study (CONCORD). Lancet Oncol. 2008;9(8): 730-56. doi:10.1016/S1470-2045(08)70179-7.

8. Sant M, Allemani C, Santaquilani M, Knijn A, Marchesi F, Capocaccia R. EUROCARE-4. Survival of cancer patients diagnosed in 1995-1999. Results and commentary. Eur J Cancer. 2009;45(6):931-91.

9. SEER Cancer Statistics Review, 1975-2010 [database on the Internet]. National Cancer Institute. 2013. Available from: http:// seer.cancer.gov/csr/1975_2010/. Accessed 11 Nov 2013. 
10. RORENO. Sobrevivência Global, Doentes diagnosticados em 200506-Região Norte. Registo Oncológico Regional do Norte. 2013; Instituto Português de Oncologia do Porto, ed. Porto, 2013

11. CDC, Prevention CfDCa. Surveillance of demographic characteristics and health behaviours among adult cancer survivors - behavioral risk factor surveillance system, United States, 2009. MMWR; 2012.

12. Hewitt M, Greenfield S, Stovall E, Editors. From cancer patient to cancer survivor: lost in transition. Committee on Cancer Survivorship: Improving Care and Quality of Life, Institute of Medicine and National Research Council; 2006.

13. Shi Q, Smith TG, Michonski JD, Stein KD, Kaw C, Cleeland CS. Symptom burden in cancer survivors 1 year after diagnosis: a report from the American Cancer Society's studies of cancer survivors. Cancer. 2011;117(12):2779-90. doi:10.1002/cncr.26146.

14. INE, INSA. Inquérito Nacional Saúde 2005/2006. Instituto Nacional Estatística, Instituto Nacional Ricardo Jorge; 2009. p. 1-330.

15. Coutinho LM, Scazufca M, Menezes PR. Methods for estimating prevalence ratios in cross-sectional studies. Rev Saude Publica. 2008;42(6):992-8.

16. Cancer prevalence statistics: approaches to estimation using cancer registry data. [database on the Internet]. Bethesda, MD: National Cancer Institute (NCI). 2010. Available from: http://srab.cancer. gov/prevalence/approaches.html. Accessed: March 4, 2011.

17. Maddams J, Brewster D, Gavin A, Steward J, Elliott J, Utley M, et al. Cancer prevalence in the United Kingdom: estimates for 2008. Br J Cancer. 2009;101(3):541-7. doi:10.1038/sj.bjc.6605148.

18. GLOBOCAN 2008 v2.0, Cancer Incidence and Mortality Worldwide [database on the Internet]. Lyon, France: International Agency for Research on Cancer. 2010. Available from: http://globocan.iarc.fr. Accessed 9 Nov 2013.

19. Desai MM, Bruce ML, Desai RA, Druss BG. Validity of self-reported cancer history: a comparison of health interview data and cancer registry records. Am J Epidemiol. 2001;153(3):299-306.

20. Fu OS, Crew KD, Jacobson JS, Greenlee H, Yu G, Campbell J, et al. Ethnicity and persistent symptom burden in breast cancer survivors. J Cancer Survivorship Res Pract. 2009;3(4):241-50. doi:10.1007/ s11764-009-0100-7.

21. Kuhnt S, Ernst J, Singer S, Ruffer JU, Kortmann RD, Stolzenburg $\mathrm{JU}$, et al. Fatigue in cancer survivors - prevalence and correlates. Onkologie. 2009;32(6):312-7. doi:10.1159/000215943.

22. Treanor C, Donnelly M. An international review of the patterns and determinants of health service utilisation by adult cancer survivors. BMC Health Serv Res. 2012;12:316. doi:10.1186/1472-6963-12316.

23. Snyder CF, Frick KD, Kantsiper ME, Peairs KS, Herbert RJ, Blackford AL, et al. Prevention, screening, and surveillance care for breast cancer survivors compared with controls: changes from 1998 to 2002. J Clin Oncol Off J Am Soc Clin Oncol. 2009;27(7): 1054-61. doi:10.1200/JCO.2008.18.0950.
24. Yabroff KR, Lawrence WF, Clauser S, Davis WW, Brown ML. Burden of illness in cancer survivors: findings from a populationbased national sample. J Natl Cancer Inst. 2004;96(17):1322-30. doi: 10.1093/jnci/djh255.

25. Travis LB. The epidemiology of second primary cancers. Cancer Epidemiol, Biomark Prev Publ Am Assoc Cancer Res Am Soc Prev Oncol. 2006;15(11):2020-6. doi:10.1158/1055-9965.EPI-060414.

26. Earle CC, Neville BA. Under use of necessary care among cancer survivors. Cancer. 2004;101(8):1712-9. doi:10.1002/cncr.20560.

27. Snyder CF, Frick KD, Peairs KS, Kantsiper ME, Herbert RJ, Blackford AL, et al. Comparing care for breast cancer survivors to non-cancer controls: a five-year longitudinal study. J Gen Intern Med. 2009;24(4):469-74. doi:10.1007/s11606-009-0903-2.

28. Cooper GS, Yuan Z, Chak A, Rimm AA. Patterns of endoscopic follow-up after surgery for nonmetastatic colorectal cancer. Gastrointest Endosc. 2000;52(1):33-8. doi:10.1067/mge.2000. 106685.

29. Earle CC, Burstein HJ, Winer EP, Weeks JC. Quality of non-breast cancer health maintenance among elderly breast cancer survivors. J Clin Oncol Off J Am Soc Clin Oncol. 2003;21(8):1447-51. doi:10. 1200/JCO.2003.03.060.

30. Yabroff KR, Short PF, Machlin S, Dowling E, Rozjabek H, Li C, et al. Access to preventive health care for cancer survivors. Am J Prev Med. 2013;45(3):304-12. doi:10.1016/j.amepre.2013.04.021.

31. Vieira M, Frutuoso A, Correia AM. Vacinação contra a Gripe Sazonal-Época 2012/2013. Administração Regional de Saúde do Norte; 2013. p. 1-2.

32. Meropol NJ, Schrag D, Smith TJ, Mulvey TM, Langdon Jr RM, Blum D, et al. American society of clinical oncology guidance statement: the cost of cancer care. J Clin Oncol Off J Am Soc Clin Oncol. 2009;27(23):3868-74. doi:10.1200/JCO.2009.23.1183.

33. Ward E, Halpern M, Schrag N, Cokkinides V, DeSantis C, Bandi P, et al. Association of insurance with cancer care utilization and outcomes. CA Cancer J Clin. 2008;58(1):9-31. doi:10.3322/CA.2007.0011.

34. Meropol NJ, Schulman KA. Cost of cancer care: issues and implications. J Clin Oncol Off J Am Soc Clin Oncol. 2007;25(2):180-6. doi: 10.1200/JCO.2006.09.6081.

35. Mols F, Thong MS, Vissers P, Nijsten T, van de Poll-Franse LV. Socio-economic implications of cancer survivorship: results from the PROFILES registry. Eur J Cancer. 2012;48(13):2037-42. doi:10. 1016/j.ejca.2011.11.030.

36. Mehnert A, de Boer A, Feuerstein M. Employment challenges for cancer survivors. Cancer. 2013;119 Suppl 11:2151-9. doi:10.1002/ cncr.28067.

37. de Boer AG, Taskila T, Tamminga SJ, Frings-Dresen MH, Feuerstein $\mathrm{M}$, Verbeek JH. Interventions to enhance return-to-work for cancer patients. The Cochrane database of systematic reviews. 2011(2): CD007569. doi:10.1002/14651858.CD007569.pub2. 